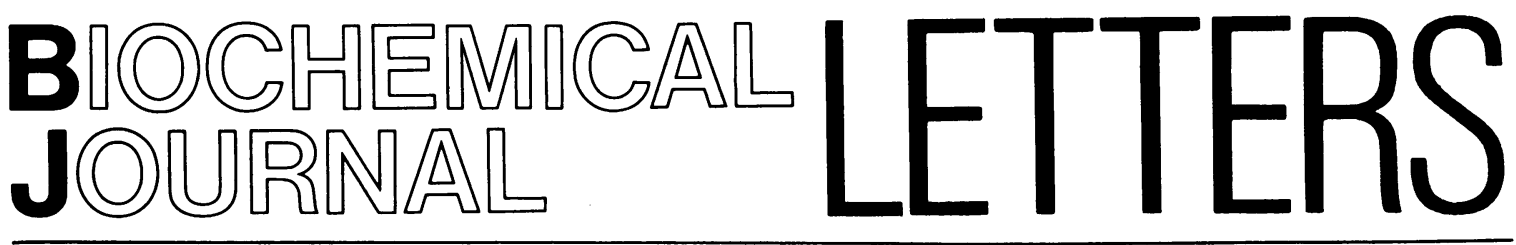

\section{Induction of 5-aminolaevulinate} synthase in chick embryo liver by propylisopropylacetamide does not involve destruction of cytochrome $P-450$

Haem biosynthesis in the liver is regulated by the activity of 5-aminolaevulinate synthase (see Elder, 1980 , for a review). This enzyme can be induced by a number of chemicals. A current view of the mechanism of induction suggests that inducing chemicals deplete a regulatory haem pool which normally represses synthesis of the enzyme (Elder, 1980). Depletion of the regulatory haem pool has been attributed to destruction of haem (e.g., by 2-allyl-2-isopropylacetamide) and to increased incorporation of haem into induced cytochrome $P-450$ (De Matteis, 1978). Recently, Lim et al. (1980) reported in this journal that, in chick embryo liver, the non-allyl containing isopropylacetamide, 2-propyl-2-isopropylacetamide, as well as allylisopropylacetamide, induce 5-aminolaevulinate synthase and produce initial decreases in hepatic microsomal cytochrome $P-450$. They proposed, therefore, that all chemicals which induce synthesis of 5-aminolaevulinate synthase do so by causing an initial depletion of cytochrome $P-450$ haem. In contrast, Krupa et al. (1974) found that allyl-, but not propyl-, isopropylacetamide caused detectable decreases in chick embryo hepatic cytochrome $P-450$.

Here we report that we are unable to confirm the findings of Lim et al. (1980). Thus, at different times up to $2.5 \mathrm{~h}$ after injection, propylisopropylacetamide did not detectably decrease microsomal cytochrome $P-450$ levels, although 5-aminolaevulinate synthase increased 4-8-fold in this period. These data were obtained from different experiments in which pooled livers were assayed $0.75,1.5$, 2 and $2.5 \mathrm{~h}$ after injection of the drug ( $2 \mathrm{mg}$ per egg) or solvent (dimethyl sulphoxide). In an attempt to enhance our ability to detect a propylisopropylacetamide-mediated decrease in cytochrome $P-450$, ferrochelatase activity, and therefore haem synthesis, was inhibited by administering a low dose $(0.15 \mathrm{mg} / \mathrm{egg})$ of dicarbethoxydihydrocollidine $8 \mathrm{~h}$ before killing (Cole et al., 1979; Rifkind, 1979); during the final $2 \mathrm{~h}$, the embryos were treated with either propylisopropylacetamide or solvent. No detectable decrease in cytochrome $P-450$ occurred under these conditions. However, in agreement with Lim et al. (1980), we did observe a decrease in cytochrome $P-450$ and an increase in 5-aminolaevulinate synthase $2 \mathrm{~h}$ after administration of a high dose of dicarbethoxydihydrocollidine $(2 \mathrm{mg}$ / egg).

These findings were sent to the authors of Lim et al., (1980) and they now report (L.-K. Lim, G. Srivastava, J. D. Brooker, B. K. May \& W. H. Elliott, personal communication) that in repeating their experiments with propylisopropylacetamide, they have not observed a reproducibly significant drop in cytochrome $P-450$ and are investigating why these results differ from those they reported earlier.

The differences between the original findings of Lim et al. (1980) and our present findings are probably due to the presence of haemoglobin in their microsomes. Cytochrome $P-450$ in our experiments was measured by the method of Omura \& Sato (1964) using microsomes washed with $0.15 \mathrm{M}-\mathrm{KCl}$ to remove excess haemoglobin [indicated by the almost total absence of a peak at $420 \mathrm{~nm}$ in the COdifference spectra (Sinclair et al., 1979)]. In contrast, the microsomes assayed by Lim et al. (1980) were not washed with $\mathrm{KCl}$. We have found that haemoglobin bound to unwashed chick hepatic microsomes (1) causes a shift in the $450 \mathrm{~nm}$ peak, (2) distorts the symmetry of the peak, and (3) when present in large amounts, causes underestimation of cytochrome $P-450$.

Using similar techniques to ours, Giger \& Meyer (1981) have not detected the decrease in cytochrome $P-450$ following phenobarbital administration reported by Lim et al. (1980). However, Giger \& Meyer (1981) could demonstrate a decrease in cytochrome $P$-450 following allylisopropylacetamide administration.

We conclude that propylisopropylacetamide does not cause a detectable decrease in cytochrome $P-450$ yet it produces rapid induction of 5-aminolaevulinate synthesis. The mechanism underlying the latter effect remains to be elucidated.

This work was supported by a grant from the National Cancer Institute (CA-25012) and by research funds from the Veterans Administration. 
Peter R. SINCLAIR, John F. HEALEY, Jacqueline F. SINCLAIR and Herbert L. BONKOWSKY

Veterans Administration Center,

White River Junction, VT 05001, U.S.A.

and Departments of Biochemistry and Medicine,

Dartmouth Medical School,

Hanover, NH 03755, U.S.A.

(Received 17 July 1981)

Cole, S. P. C., Vavasour, E. J. \& Marks, G. S. (1979) Biochem. Pharmacol. 28, 3533-3538

De Matteis, F. (1978) Handb. Exp. Pharmacol. 44, 129 150

Elder, G. H. (1980) in Iron in Biochemistry and Medicine II (Jacobs, A. \& Worwood, M., eds.), pp. 245-292, Academic Press, New York
Giger, U. \& Meyer, U. A. (1981) Biochem. J. 198, 321329

Krupa, V., Creighton, J. C., Freeman, M. \& Marks, G. S. (1974) Can. J. Physiol. Pharmacol. 52 , 891-895

Lim, L.-K., Srivastava, G., Brooker, J. D., May, B. K. \& Elliott, W. H. (1980) Biochem. J. 190, 519-526

Omura, T. \& Sato, R. (1964) J. Biol. Chem. 239, 23702385

Rifkind, A. B .(1979) J. Biol. Chem. 254, 4636-4644

Sinclair, J. F., Sinclair, P. \& Bonkowsky, H. (1979) Biochem. Biophys. Res. Commun. 84, 710-717

0306-3283/81/120709-02\$01.50/1

(C) 1981 The Biochemical Society 